\title{
ORIGINAL ARTICLE Obesity and carotid artery remodeling
}

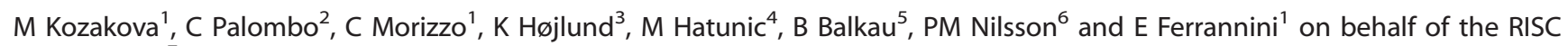 \\ Investigators ${ }^{7}$
}

BACKGROUND/OBJECTIVE: The present study tested the hypothesis that obesity-related changes in carotid intima-media thickness (IMT) might represent not only preclinical atherosclerosis but an adaptive remodeling meant to preserve circumferential wall stress (CWS) in altered hemodynamic conditions characterized by body size-dependent increase in stroke volume (SV) and blood pressure (BP). SUBJECTS/METHODS: Common carotid artery (CCA) luminal diameter (LD), IMT and CWS were measured in three different populations in order to study: (A) cross-sectional associations between SV, BP, anthropometric parameters and CCA LD (266 healthy subjects with wide range of body weight (24-159 kg)); (B) longitudinal associations between CCA LD and 3-year IMT progression rate ( $\triangle I M T ; 571$ healthy non-obese subjects without increased cardiovascular (CV) risk); (C) the impact of obesity on CCA geometry and CWS (88 obese subjects without CV complications and 88 non-obese subjects matched for gender and age).

RESULTS: CCA LD was independently associated with SV that was determined by body size. In the longitudinal study, baseline LD was an independent determinant of $\triangle \mathrm{IMT}$, and $\triangle \mathrm{IMT}$ of subjects in the highest LD quartile was significantly higher ( $28 \pm 3 \mu \mathrm{m})$ as compared with those in the lower quartiles $(8 \pm 3,16 \pm 4$ and $16 \pm 3 \mu \mathrm{m}, P=0.001, P<0.05$ and $P=0.01$, respectively). In addition, CCA CWS decreased during the observational period in the highest LD quartile (from $54.2 \pm 8.6$ to $51.6 \pm 7.4 \mathrm{kPa}, P<0.0001$ ). As compared with gender- and age-matched lean individuals, obese subjects had highly increased CCA LD and BP $(P<0.0001$ for both), but only slightly higher CWS $(P=0.05)$ due to a significant increase in IMT $(P=0.005$ after adjustment for confounders). CONCLUSIONS: Our findings suggest that in obese subjects, the CCA wall thickens to compensate the luminal enlargement caused by body size-induced increase in SV, and therefore, to normalize the wall stress. CCA diameter in obesity could represent an additional biomarker, depicting the impact of altered hemodynamics on arterial wall.

Nutrition \& Diabetes (2015) 5, e177; doi:10.1038/nutd.2015.26; published online 24 August 2015

\section{INTRODUCTION}

Obesity is an independent risk factor for cardiovascular (CV) disease $^{1,2}$ and an obesity-related increase in carotid intima-media thickness (IMT) $)^{3,4}$ is usually interpreted as a sign of subclinical atherosclerosis. However, obesity is accompanied not only by an alteration in the metabolic profile but also by changes in systemic hemodynamics that are necessary to satisfy the metabolic demand of expanded body mass and that comprise increase in blood pressure (BP), ${ }^{5,6}$ heart rate and stroke volume (SV)..$^{7-9}$ Hemodynamics has a fundamental role in controlling arterial geometry. Physiologically, arterial wall remodels in response to persistent alterations in blood flow ${ }^{10-12}$ and pressure, ${ }^{13,14}$ thus keeping wall shear stress and circumferential wall stress (CWS) within homeostatic targets. ${ }^{15}$ In obesity, a body size-related increase in SV can be expected to increase luminal diameter ${ }^{11,16,17}$ in order to maintain the shear stress; ${ }^{18-20}$ yet an increase in luminal diameter and systemic pressure augments CWS and may induce carotid wall thickening aimed to normalize the stress. ${ }^{21-24}$

Therefore, in the present study we tested the hypothesis that obesity-related changes in IMT might represent not only preclinical atherosclerosis but also an adaptive remodeling meant to preserve CWS in altered hemodynamic conditions. For this purpose we performed several analyses in three different populations. (A) The inter-relationships between anthropometric parameters, SV, BP, luminal diameter and IMT were studied in a healthy population with a wide range of age and body size. (B) The relationships between carotid luminal diameter, IMT and a 3-year IMT progression rate $(\Delta \mathrm{IMT})$ were evaluated in apparently healthy non-obese young-to-middle-aged men and women free of carotid atherosclerosis and without increased CV risk and metabolic syndrome at baseline and at 3 years. (C) Carotid IMT, luminal diameter and CWS were compared between obese subjects free of CV complications and healthy controls, matched for gender and age. The above-described relationships were studied in the proximal segment of the common carotid artery (CCA) as its simple cylindrical geometry and linear blood flow allows the application of Laplace's law for wall stress calculation.

\section{MATERIALS AND METHODS}

Study populations

Three different populations were studied: (A) Two-hundred and sixty-six apparently healthy subjects (children, adolescents and adults), free of CV disease, carotid plaques, diabetes, antihypertensive and lipid-lowering therapies, with a wide range of age (from 8 to 77 years) and body weight (from 24 to $159 \mathrm{~kg}$ ), were recruited in a single center (Pisa).

(B) Five-hundred and seventy-one apparently healthy non-obese subjects with a low-average CV risk (assessed by the Framingham risk score) and free of the metabolic syndrome and carotid plaque at baseline and at 3 years selected from the 1566 participants of the Relationship between Insulin Sensitivity and Cardiovascular Risk (RISC)

\footnotetext{
${ }^{1}$ Department of Clinical and Experimental Medicine, University of Pisa, Pisa, Italy; ${ }^{2}$ Department of Surgical, Medical, Molecular Pathology and Critical Care, University of Pisa, Pisa, Italy; ${ }^{3}$ Department of Endocrinology, Odense University Hospital, Odense, Denmark; ${ }^{4}$ Mater Misericordiae University Hospital, Dublin, Ireland; ${ }^{5}$ INSERM, CESP, Center for Research in Epidemiology and Population Health, U1018, University Paris Sud, Villejuif, France and ${ }^{6}$ Department of Clinical Science, Lund University, Skåne University Hospital, Malmö, Sweden. Correspondence: Dr M Kozakova, Department of Clinical and Experimental Medicine University of Pisa, Via Roma, 67, Pisa 56122, Italy.

E-mail: m.kozakova@int.med.unipi.it

${ }^{7}$ The members of the RISC Investigators are listed above references.

Received 6 June 2015; accepted 18 June 2015
} 
Study (www.egir.org) that recruited healthy Caucasians in 19 centers in 14 European countries. Inclusion criteria of this longitudinal study, as well as power calculation, were previously reported. ${ }^{25}$

(C) Eighty-eight obese subjects (children, adolescents and adults) free of CV complications and carotid plaques and 88 apparently healthy volunteers, matched for gender and age, were recruited in a single center (Pisa).

\section{Study protocol}

The examination protocol of all three studies included medical history, anthropometry, brachial BP measurements, resting ECG, a fasting blood test, high-resolution ultrasound of extracranial carotid arteries and, for the first study population, cardiac ultrasound for SV assessment. Information regarding medical history, drug use and smoking habit was collected directly by a physician (in Pisa populations) or using standardized selfreported questionnaires (in the RISC study). A relative risk for coronary heart disease over a 10-year period was estimated from the Framingham Heart Study risk score sheets and graded as low, below average, average, above average or high. ${ }^{26}$ The metabolic syndrome was defined according to the US National Cholesterol Education Program Adult Treatment Panel $\mathrm{III}^{27}$ as the presence of at least three out of five metabolic syndrome components (waist circumference (WC) $>102 \mathrm{~cm}$ in men and $>88 \mathrm{~cm}$ in women; $B P \geqslant 130 / 85 \mathrm{~mm} \mathrm{Hg}$; high-density lipoprotein cholesterol $<1.03 \mathrm{mmoll}^{-1}$ in men and $<1.29 \mathrm{mmoll}^{-1}$ in women; triglycerides $\geqslant 1.7 \mathrm{mmoll}^{-1}$; fasting glucose $\geqslant 6.1 \mathrm{mmoll}^{-1}$ ). The study protocols conformed to the ethical guidelines of the 1975 Declaration of Helsinki Principles and was approved by local ethics committee in each center Written consent was obtained from all participants.

\section{Carotid artery ultrasound imaging and analysis}

Carotid ultrasound was performed according to current guidelines in all three studies. ${ }^{28}$ Briefly, longitudinal B-mode images of the left and right CCA, carotid bifurcation and internal carotid artery were recorded from anterior, lateral and posterior angle by a high-resolution B-mode ultrasound. The analysis of carotid images was performed using the computer-driven image analysis system MIP (Medical Image Processing Institute of Clinical Physiology, CNR, Pisa, Italy). End-diastolic frames of the right CCA in longitudinal projection with a well-defined intima-media complex of the near and far wall were selected and digitized with a resolution of $576 \times 768$ pixels, and 256 -degree gray scale per pixel. In the digitized image, the far-wall IMT and the luminal diameter (inner diameter that is, distance between the lumen-intima interfaces of the near and far wall) were measured in a $1-\mathrm{cm}$ long straight segment, $\sim 1 \mathrm{~cm}$ before the flow divider. The value reported represents the average of three cardiac cycles. End-diastolic CWS was calculated with Lamé's equation as the product between diastolic $\mathrm{BP}$ ( $\mathrm{DBP}$ in $\mathrm{kPa}$ ) measured during image acquisition on the left brachial artery (Omron, model $705 \mathrm{cp}$, Kyoto, Japan) and the ratio of end-diastolic luminal radius ( $r=$ diameter/2) to enddiastolic far-wall IMT (end-diastolic $r /$ IMT): end-diastolic CWS $(\mathrm{kPa})=\mathrm{DBP} \times$ end-diastolic $r / \mathrm{IMT}^{22}$

In the multicenter study, carotid scans were acquired in each recruiting center by trained and certified technicians, while the analysis of carotid images was completed in a reading center (Pisa) by a single reader (MK), as previously described. Intra-observer variability of IMT and diameter measurements as well as inter-test IMT variability were tested and are previously reported. ${ }^{23,29}$

\section{Cardiac ultrasound}

SV was assessed by transthoracic Doppler-echocardiography as the product of aortic valve cross-sectional area and trans-aortic flow velocitytime integral. ${ }^{9}$ Trans-aortic flow was obtained in the apical projection, aortic valve opening was measured in the long-axis view and aortic valve area was calculated by circular geometry. The values used for statistical analysis are averaged over five consecutive cardiac beats. Intra-observer variability of SV measurement in our laboratory was previously reported. ${ }^{23}$

\section{Anthropometric and BP measurement}

Height and weight were measured, and body mass index (BMI) was calculated as body weight (in $\mathrm{kg}$ ) divided by squared height (in meters). In adults, obesity was defined as BMI $\geqslant 30 \mathrm{~kg} \mathrm{~m}^{-2}$; in children and adolescents obesity was defined as $\mathrm{BMI} \geqslant 95$ th percentile of value reported for gender and age in BMI-for-age percentiles charts. ${ }^{30}$ WC was measured as the narrowest circumference between the lower rib margin and anterior superior iliac crest. Office brachial BP was measured by a digital electronic tensiometer (Omron, model 705cp, Kyoto, Japan, regular or large adult cuffs according to the arm circumference) in subjects seated for at least $10 \mathrm{~min}$. The reported values are the mean of two measurements performed during two different visits.

\section{Analytical procedures}

All biochemical parameters were determined by standard methods on a Roche-Modular System (Basel, Switzerland). In the multicenter study, all biochemical analyses were performed in a single center. ${ }^{25}$

\section{Statistical analysis}

Data are expressed as mean \pm s.d., mean \pm s.e. and categorical data as percentages.

Variables with a skewed distribution are summarized as median and interquartile range, and log transformed for parametric statistical analyses. Analysis of covariance and Wilcoxon signed-rank test or Student's $t$-test were used to compare continuous variables, and $x^{2}$-test to compare binary variables. Relations between the outcome variables (CCA IMT, $\triangle \mathrm{IMT}$ and luminal diameter) and continuous variables were evaluated by univariate Pearson's correlation coefficients $(r)$. Multiple linear regression with backward removal (adjusted for center in the multicenter study) was used to test the independent association of outcome variables with their significant univariate correlates. Statistical tests were two-sided and significance was set at a value of $P<0.05$. Statistical analysis was performed by JMP software, version 3.1 (SAS Institute Inc., Cary, NC, USA).

\section{RESULTS}

Cross-sectional study evaluating the relationship between anthropometric parameters, SV, BP, CCA luminal diameter and IMT In 266 apparently healthy subjects with a wide range of age and body weight (Supplementary Table 1), SV was directly related to body weight (Figure 1), height, BMI, WC ( $r=0.50,0.33$ and 0.28 , $P<0.0001$ for all), age $(r=0.33, P<0.0001)$, systolic BP (SBP) and $\operatorname{DBP}(r=0.34$ and $0.20, P<0.0001$ and $P=0.001)$. SBP was directly related to body weight (Figure 1$)$, height, BMI, WC ( $r=0.31,0.30$ and $0.30, P<0.0001$ for all), age $(r=0.43, P<0.0001)$ and plasma glucose $(r=0.25, P<0.001)$. In multivariate models, following backward stepwise removal of variables, SV was determined by age, body height and body weight, and SBP was determined by male gender, age and body weight (Table 1).

CCA luminal diameter increased with SV and body weight (Figure 1), height, BMI and WC $(r=0.43,0.41$ and $0.45, P<0.0001$ for all), age $(r=0.56, P<0.0001)$, SBP and DBP $(r=0.41$ and 0.38 , $P<0.0001$ for both) and plasma glucose $(r=0.26, P<0.0005)$. CCA IMT increased with age $(r=0.73, P<0.0001)$, luminal diameter (Figure 1), SBP (Figure 1) and DBP $(r=0.34, P<0.0001)$, lowdensity lipoprotein cholesterol, triglycerides and plasma glucose $(r=0.27,0.32$ and $0.25, P<0.001-0.0001)$. In a multivariate model, luminal diameter was determined by male gender, age, WC and SV; when body weight was included in the model, it replaced SV and WC (Table 2a). CCA IMT was independently associated with age, luminal diameter and SBP (Table 2a).

Longitudinal and cross-sectional study evaluating the relationship between baseline CCA luminal diameter and IMT or 3-year IMT progression rate

In 571 healthy non-obese subjects without increased CV risk and metabolic syndrome, BP components and established atherosclerotic risk factors remained stable during the observational period of 3 years, whereas body weight, BMI, WC and fasting plasma glucose slightly increased (Supplementary Table 2).

Cross-sectional data. Univariate correlates of baseline CCA IMT and luminal diameter are reported in Table 3 . In a multiple regression model adjusted for centers, baseline CCA IMT was 

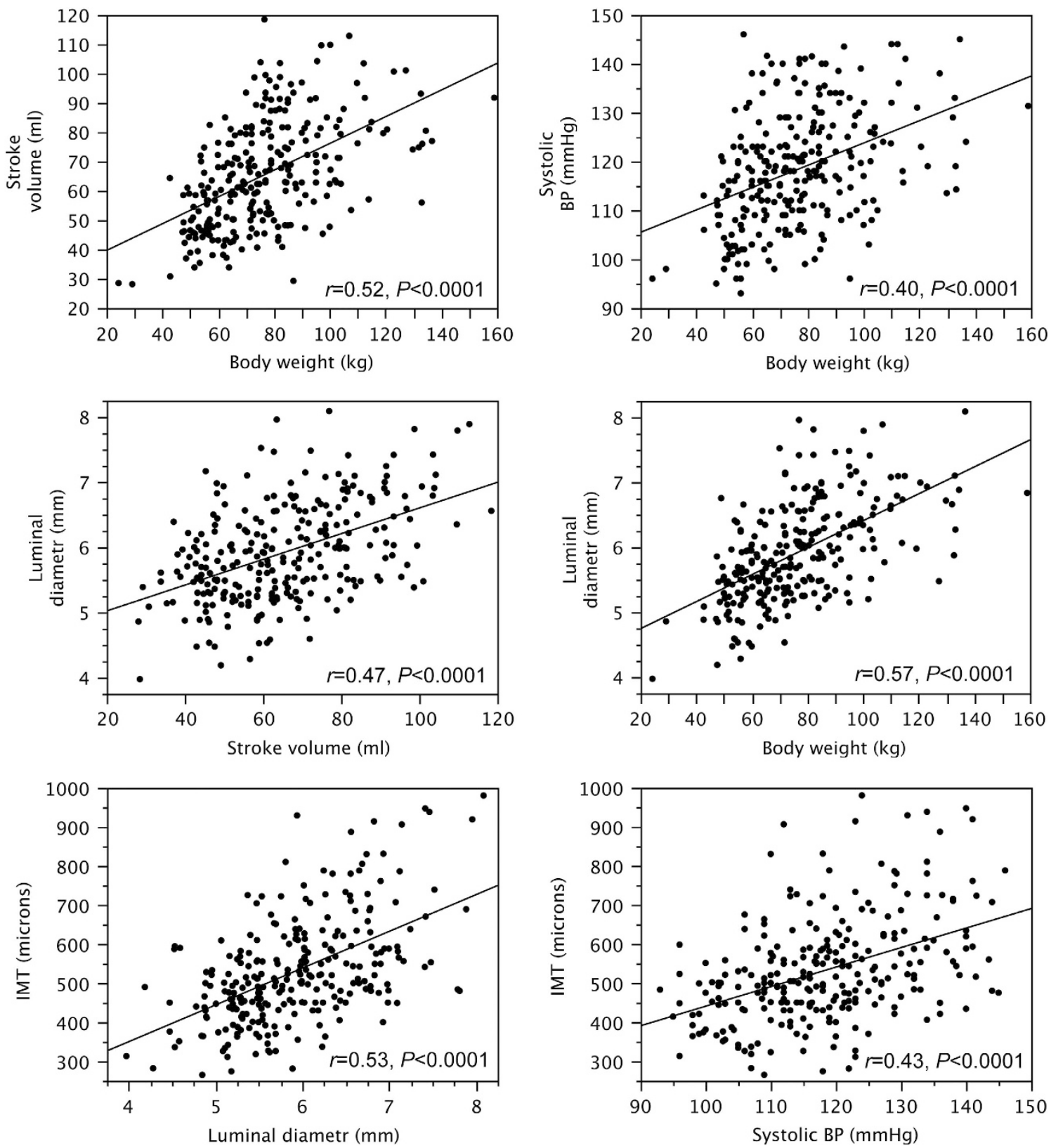

Figure 1. Correlations between body weight, stroke volume, blood pressure, CCA luminal diameter and IMT in 266 apparently healthy subjects.

Table 1. Independent determinants of stroke volume and systolic blood pressure in apparently healthy population with wide range of age and body weight

\begin{tabular}{llcc}
\hline & & ${ }^{*} \beta \pm$ s.e. & P-value \\
\hline Stroke volume $(\mathrm{ml})$ & Age (years) & $0.17 \pm 0.05$ & 0.001 \\
& Body weight $(\mathrm{kg})$ & $0.36 \pm 0.05$ & $<0.0001$ \\
& Body height $(\mathrm{m})$ & $0.28 \pm 0.06$ & $<0.0001$ \\
& & 0.38 & $<0.0001$ \\
Cumulative $R^{2}$ & & $0.15 \pm 0.05$ & $<0.01$ \\
Systolic BP $(\mathrm{mmHg})$ & Gender (male) & $0.36 \pm 0.05$ & $<0.0001$ \\
& Age (years) & $0.31 \pm 0.05$ & $<0.0001$ \\
& Body weight $(\mathrm{kg})$ & 0.31 & $<0.0001$ \\
\hline
\end{tabular}

$* \beta=$ standardized regression coefficient. independently related to age, luminal diameter, SBP and total cholesterol, and baseline luminal diameter was independently related to male gender, age and body weight (Table $2 \mathrm{~b}$ ).

Longitudinal data. During a 3-year period, carotid IMT significantly increased (from $594 \pm 75$ to $611 \pm 77 \mu \mathrm{m} \quad P<0.0001$ ), and end-diastolic wall stress decreased (from $47.7 \pm 8.6$ to $46.8 \pm 7.8 \mathrm{kPa}, P<0.005)$. $\triangle \mathrm{IMT}$ was directly related to age, baseline CCA diameter and plasma total and low-density lipoprotein cholesterol, and inversely to the baseline CCA IMT (Table 3), whereas it was not related to 3-year changes in atherosclerotic risk factors. In a multiple regression model adjusted for centers, the independent determinants of $\triangle I M T$ were age, baseline luminal diameter, baseline IMT and total plasma cholesterol (Table 2b). 
Table 2. Independent determinants of CCA IMT, $\triangle \mathrm{IMT}$ and luminal diameter

\begin{tabular}{|c|c|c|c|c|c|c|}
\hline & \multicolumn{2}{|c|}{ Baseline CCA IMT ( $\mu \mathrm{m})$} & \multicolumn{2}{|c|}{$\triangle C C A I M T(\mu m)$} & \multicolumn{2}{|c|}{ Baseline luminal diameter ( $\mathrm{mm}$ ) } \\
\hline \multicolumn{7}{|c|}{ a) Healthy population with wide range of age and body size; $\mathrm{N}=266$} \\
\hline Age (years) & $0.58 \pm 0.05$ & $<0.0001$ & & & $0.42 \pm 0.05$ & $<0.0001$ \\
\hline Waist circumference $(\mathrm{cm})$ & & & & & $0.25 \pm 0.05$ & $<0.0001$ \\
\hline Stroke volume $(\mathrm{ml})$ & & & & & $0.19 \pm 0.05$ & $<0.0001$ \\
\hline Cumulative $R^{2}$ & 0.56 & $<0.0001$ & & & 0.51 & $<0.0001$ \\
\hline Gender (male) & & & & & $0.16 \pm 0.04$ & $<0.0001$ \\
\hline Age (years) & & & & & $0.45 \pm 0.04$ & $<0.0001$ \\
\hline Body weight (kg) & & & & & $0.43 \pm 0.04$ & $<0.0001$ \\
\hline Cumulative $R^{2}$ & & & & & $0 . \overline{5} 7$ & $<0.0001$ \\
\hline \multicolumn{7}{|c|}{ b) Healthy non-obese population without increased cardiovascular risk; $\mathrm{N}=571$} \\
\hline Systolic BP (mm Hg) & $0.09 \pm 0.04$ & 0.01 & & & & \\
\hline Total cholesterol $\left(\mathrm{mmoll}^{-1}\right)$ & $0.11 \pm 0.04$ & $<0.005$ & $0.12 \pm 0.04$ & $<0.005$ & & \\
\hline Cumulative $R^{2}$ & 0.36 & $<0.0001$ & 0.25 & $<0.0001$ & 0.32 & $<0.0001$ \\
\hline
\end{tabular}

Table 3. Univariate correlations between carotid structural measures, anthropometric parameters and risk factors in 571 non-obese healthy subjects

\begin{tabular}{|c|c|c|c|}
\hline & Baseline CCA IMT $(\mu \mathrm{m})$ & $\triangle C C A$ IMT $(\mu m)$ & Baseline luminal diameter $(\mathrm{mm})$ \\
\hline Baseline diameter (mm) & 0.23 & 0.17 & - \\
\hline BMI $\left(\mathrm{kg} \mathrm{m}^{-2}\right)$ & 0.18 & NS & 0.30 \\
\hline Body weight $(\mathrm{kg})$ & 0.15 & NS & 0.47 \\
\hline Waist circumference $(\mathrm{cm})$ & 0.22 & NS & 0.42 \\
\hline Systolic BP (mm Hg) & 0.21 & NS & 0.23 \\
\hline LDL-cholesterol $\left(\mathrm{mmoll}^{-1}\right)$ & 0.27 & 0.10 & NS \\
\hline $\mathrm{HDL}$-cholesterol $\left(\mathrm{mmoll}^{-1}\right)$ & NS & NS & -0.19 \\
\hline Triglycerides $\left(\mathrm{mmoll}^{-1}\right)$ & 0.15 & NS & 0.15 \\
\hline Fasting glucose $\left(\mathrm{mmoll}^{-1}\right)$ & 0.13 & NS & 0.29 \\
\hline Fasting insulin $\left(\mathrm{pmolI}^{-1}\right)$ & NS & NS & NS \\
\hline
\end{tabular}

Abbreviations: BP, blood pressure; BMI, body mass index; CCA, common carotid artery; HDL, high-density lipoprotein; IMT, intima-media thickness; LDL, lowdensity lipoprotein; NS, not significant.

The distribution of $\triangle \mathrm{IMT}$, body weight and changes in CWS were evaluated also by quartiles of baseline luminal diameter. $\triangle \mathrm{IMT}$ as well as body weight were significantly higher ( $P$-value after adjustment for center, gender and age) in the highest diameter quartile as compared with lower quartiles of luminal diameter (Figure 2a and b). CWS did not change during the 3-year period in the first two quartiles of luminal diameter, whereas in the third and above all in the fourth quartile the wall stress decreased (Figure 2c).

Case-control study evaluating CCA geometry and wall stress in obese and non-obese subjects

Carotid geometry was compared between 88 obese children, adolescents and adults without CV complications, and 88 healthy non-obese volunteers matched for gender and age
(Supplementary Table 3). CCA IMT was higher in obese subjects as compared with controls, and the difference between the two groups remained highly significant $(P=0.005)$ after adjustment for $\mathrm{BP}$ and metabolic variables (Table 4). Obese subjects had also significantly higher CCA luminal diameter and DBP $(P<0.0001$ for both), whereas end-diastolic CWS was only slightly increased $(P=0.05)$.

\section{DISCUSSION}

Altogether, our findings suggest that in obese subjects carotid artery wall thickens to compensate the luminal enlargement and BP increase related to expansion of body mass, thus preventing a significant increase in CWS. However, our data were obtained in healthy population without increased CV risk and in obese 
a

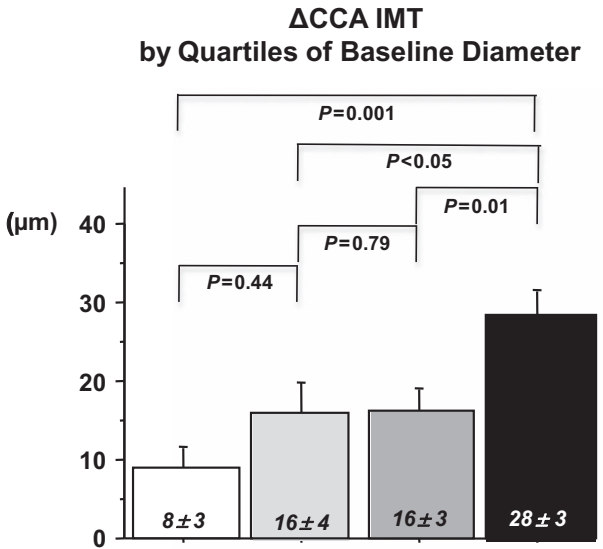

Diameter $(\mathrm{mm}) \quad(4.0-5.25) \quad(>5.25-5.65)(>5.65-6.15) \quad(>6.15)$ b

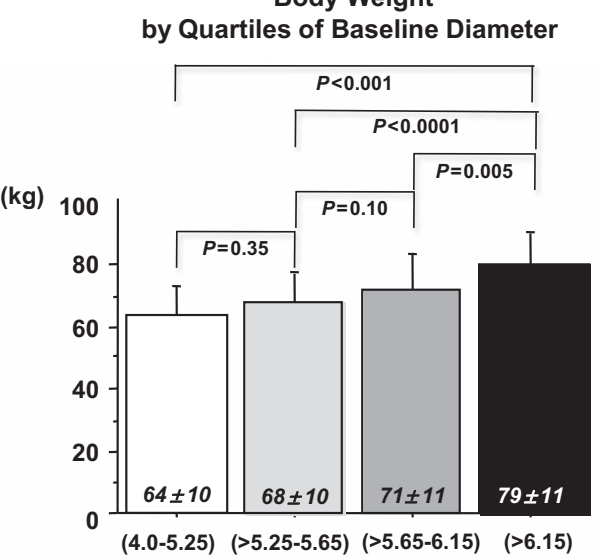

Cnd-diastolic

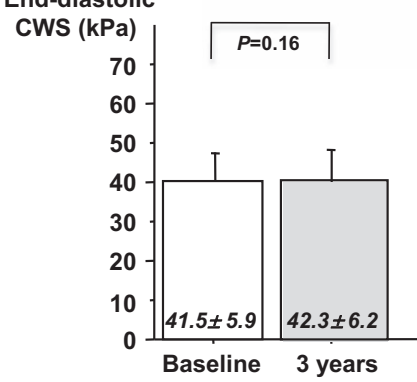

Diameter (mm)

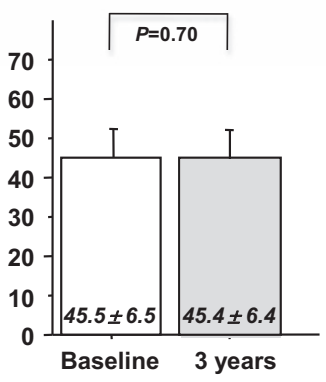

$(>5.25-5.65)$

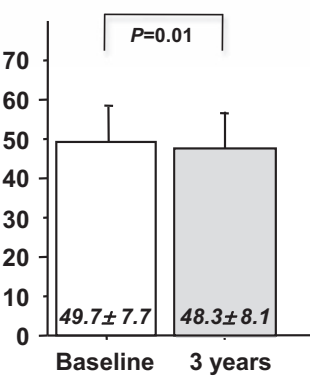

$(>5.65-6.15)$

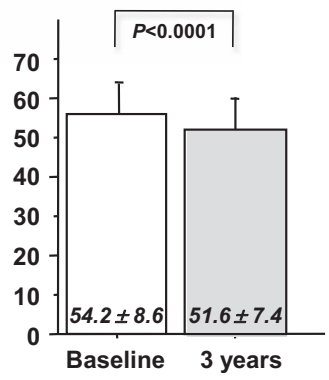

$(>6.15)$

Figure 2. (a and b) Distribution of $\Delta \mathrm{IMT}$ (mean \pm s.e.) and baseline body weight (mean \pm s.d.) by quartiles of baseline luminal diameter in 571 apparently healthy non-obese subjects. Statistical significance is reported after adjustment for center, sex and age. (c) End-diastolic circumferential wall stress (CWS; mean \pm s.d.) at baseline and at 3 years by quartiles of baseline luminal diameter in 571 apparently healthy non-obese subjects.

Table 4. CCA IMT, luminal diameter, circumferential wall stress in non-obese and in obese subjects matched for gender and age

\begin{tabular}{lcccl}
\hline & Non-obese & Obese & P-value & P-value after adjustment \\
\hline CCA IMT $(\mu \mathrm{m})$ & $516 \pm 89$ & $615 \pm 122$ & $<0.0001$ & 0.0005 adjustment for BP \\
& & & 0.001 adjustment for BP and plasma lipids \\
& & & 0.005 adjustment for BP, plasma lipids and FPG \\
Luminal diameter $(\mathrm{mm})$ & $5.53 \pm 0.48$ & $6.23 \pm 0.71$ & $<0.0001$ & \\
Diastolic BP $(\mathrm{mm} \mathrm{Hg)}$ & $70 \pm 8$ & $78 \pm 11$ & $<0.0001$ & \\
End-diastolic CWS $(\mathrm{kPa})$ & $50.8 \pm 9.4$ & $53.8 \pm 13.3$ & 0.05 & \\
\hline
\end{tabular}

Abbreviations: BP, blood pressure; CCA, common carotid artery; CWS, circumferential wall stress; FPG, fasting plasma glucose ; IMT, intima-media thickness.

subjects free of CV complications and may not be extrapolated to populations at higher risk or with CV disease.

Experimental studies have clearly demonstrated that arterial wall stress is maintained stable by a mutual adjustment between luminal diameter and wall thickness, ${ }^{31-33}$ and several clinical cross-sectional studies have shown an independent association between CCA IMT and luminal diameter. ${ }^{21-23,34-36}$ We have expanded the previous findings by the observation that in a healthy non-obese population with limited impact of CV risk factors, luminal diameter was an independent determinant of IMT progression rate. In addition, subjects in the highest quartile of luminal diameter had significantly higher 3-year IMT increase as compared with those in lower quartiles, which resulted in reduction of end-diastolic CWS in this subgroup during the observational period (Figure 2).

The adjustment between arterial lumen and wall thickness is reciprocal and some studies have suggested that compensatory luminal enlargement might occur in response to arterial wall thickening. ${ }^{34,36}$ Yet, in obese subjects without carotid stenosis and CV complications, the luminal enlargement that is supposed to reflect the response to body size-related increase in blood flow ${ }^{11}$ could be considered the initial abnormality. It has been demonstrated that a chronic increase in blood flow stimulates outward arterial remodeling aimed to maintain wall shear stress, while increasing the circumferential stress. ${ }^{18,19}$ In the present study, we did not assess local carotid blood flow and wall shear stress, but we have observed a direct independent association between anthropometric parameters and SV, as well as between carotid diameter and SV or body weight, respectively (Tables 1 and 2). ${ }^{9,11}$ Even in a healthy non-obese population, body weight was the strongest determinant of luminal diameter and subjects with luminal diameter in the highest quartile had significantly higher body weight (Table 2 and Figure 2).

Thus, if carotid diameter determines the changes in carotid wall thickness, the obesity-related increase in luminal diameter and BP could induce IMT thickening aimed to reduce wall stress. In our 
case-control study, obese subjects had highly increased both luminal diameter and BP ( $P<0.0001$ for both) as compared with gender- and age-matched lean controls, yet the CWS was only slightly increased $(P=0.05)$, as obese subjects had also significantly higher IMT (Table 4). These data suggest the adaptive wall thickening, and are in line with a recent study of Kappus et al. ${ }^{37}$ showing that young obese men had increased local carotid BP, carotid diameter and IMT as compared with overweight and normal weight individuals.

The hypothesis on arterial adaptation to body size-related changes in hemodynamic load is indirectly supported by the results of several large population studies. In the Cardiovascular Risk in Young Finns Study, ${ }^{38}$ as well as in the Bogalusa study, ${ }^{39}$ the association between youth BMI and adult IMT was mediated by tracking of body mass from youth to adulthood; subjects who had been obese in youth but were non-obese as adults had IMT values comparable to subjects who had been consistently non-obese from childhood to adulthood, whereas subjects who had remained obese from childhood to adulthood had increased IMT. Furthermore, in the Cardiovascular Risk in Young Finns Study, the association between adult BMI and carotid IMT remained significant and of similar magnitude after adjustment for several metabolic risk factors, such as low-density and high-density lipoprotein cholesterol, triglycerides, insulin and C-reactive protein. ${ }^{38}$ In the Avon Longitudinal Study of Parents and Children, ${ }^{40}$ that evaluated the impact of obesity on arterial function, obese children had increased brachial artery diameter, resting and hyperemic flow and flow-mediated dilation and reduced arterial stiffness as compared with normal weight children. Observed changes were explained by physiologic adaptation to the hyperemic/hyperdynamic state of obesity.

It is worth to note the similarity between arterial and left ventricular (LV) adaptation in obesity. Obesity-related increase in circulating blood volume is associated with LV remodeling in the form of cavity dilation and compensatory LV hypertrophy, the latter representing a response to increased wall stress. ${ }^{41-44}$ Cardiac magnetic resonance-based studies have demonstrated that over $75 \%$ of LV mass cross-sectional variation in subjects free of CV risk factors can be explained by lean mass, SV and abdominal visceral $\mathrm{fat}^{43}$ and that increase in LV end-diastolic wall stress leads to LV hypertrophic response aimed to compensate for LV dilation. ${ }^{44}$ On the other hand, some growth factors related to obesity, such as insulin-like growth factor-1, insulin-like growth factor-binding protein-3 and fibroblast growth factor, ${ }^{45,46}$ may also participate on IMT thickening and LV hypertrophy in obese subjects, as their relationship to preclinical atherosclerosis or LV mass has been recognized. ${ }^{47-49}$

\section{Study limitations}

DBP used for the calculation of CWS in carotid artery was measured at brachial and not carotid artery level. However, it is known that DBP, in contrast to SBP, does not change substantially throughout the arterial tree. ${ }^{50}$ Wall shear stress, that could better explain the association between obesity, SV and luminal diameter, was not assessed. Only established risk factors were evaluated in our populations, and the impact of other risk factors, such as lipoproteins, adipocytokines, insulin resistance or chronic inflammation, on carotid wall thickness cannot be excluded.

\section{CONCLUSIONS}

Results of our cross-sectional, longitudinal and case-control studies support the postulate that an increase in carotid wall thickness in obesity should not be simply interpreted as accelerated atherosclerosis, but an adaptive remodeling aimed to normalize increased CWS caused by body size-related increase in BP, SV and luminal diameter, should also be considered.
Therefore, in obesity, carotid luminal diameter enlargement might represent an additional marker of CV risk that reflects the adverse impact of hemodynamic overload on vascular system. Our data also indicate that the weight reduction should be the most effective measure for reversing carotid wall thickening in obesity, as it is the only way to normalize central resting hemodynamics. ${ }^{9,51}$

\section{CONFLICT OF INTEREST}

The authors declare no conflict of interest.

\section{ACKNOWLEDGEMENTS}

The European Group for the Study of Insulin Resistance (EGIR) RISC study was partly supported by EU grant QLG1-CT-2001-01252. Study on obese subjects is a part of the Italian Ministry of Health Project 'Perioperative Optimization of Care in Obesity: Acronym: POCO' Project Code: RF-2010-2312316.

\section{RISC INVESTIGATORS}

RISC recruiting centers:

Amsterdam, The Netherlands: RJ Heine, J Dekker, S de Rooij, G Nijpels, W Boorsma

Athens, Greece: A Mitrakou, S Tournis, K Kyriakopoulou, $P$ Thomakos

Belgrade, Serbia and Montenegro: N Lalic, K Lalic, A Jotic, L Lukic, M Civcic

Dublin, Ireland: J Nolan, TP Yeow, M Murphy, C DeLong, G Neary, MP Colgan, M Hatunic

Frankfurt, Germany: T Konrad, H Böhles, S Fuellert, F Baer, $\mathrm{H}$ Zuchhold

Geneva, Switzerland: A Golay, E Harsch Bobbioni,V Barthassat, $\checkmark$ Makoundou, TNO Lehmann, T Merminod

Glasgow, Scotland: JR Petrie (now Dundee), C Perry, F Neary, C MacDougall, K Shields, L Malcolm

Kuopio, Finland: M Laakso, U Salmenniemi, A Aura, R Raisanen, $\mathrm{U}$ Ruotsalainen, $\mathrm{T}$ Sistonen, $\mathrm{M}$ Laitinen, $\mathrm{H}$ Saloranta

London, UK: SW Coppack, N Mclntosh, J Ross, L Pettersson, P Khadobaksh

Lyon, France: M Laville, F Bonnet, A Brac de la Perriere, C Louche-Pelissier, C Maitrepierre, J Peyrat, S Beltran, A Serusclat

Madrid, Spain: R Gabriel, EM Sánchez, R Carraro, A Friera, B Novella

Malmö, Sweden (1): P Nilsson, M Persson, G Östling, (2): O Melander, P Burri

Milan, Italy: PM Piatti, LD Monti, E Setola, E Galluccio, F Minicucci, A Colleluori

Newcastle-upon-Tyne, UK: M Walker, IM Ibrahim, M Jayapaul, D Carman, C Ryan, K Short, Y McGrady, D Richardson

Odense, Denmark: H Beck-Nielsen, P Staehr, K Hojlund, V Vestergaard, C Olsen, L Hansen

Perugia, Italy: GB Bolli, F Porcellati, C Fanelli, P Lucidi, F Calcinaro, A Saturni

Pisa, Italy: E Ferrannini, A Natali, E Muscelli, S Pinnola, M Kozakova

Rome, Italy: G Mingrone, C Guidone, A Favuzzi, P Di Rocco

Vienna, Austria: C Anderwald, M Bischof, M Promintzer, M Krebs, M Mandl, A Hofer, A Luger, W Waldhäusl, M Roden.

\section{Project Management Board:}

B Balkau (Villejuif, France), SW Coppack (London, UK), JM Dekker (Amsterdam, The Netherlands), E Ferrannini (Pisa, Italy), A Mari (Padova, Italy), A Natali (Pisa, Italy), M Walker (Newcastle, UK).

\section{Core laboratories and reading centres:}

Lipids Dublin, Ireland: P Gaffney, J Nolan, G Boran

Hormones Odense, Denmark: C Olsen, L Hansen, H Beck-Nielsen 
Albumin:creatinine, Amsterdam, The Netherlands: A Kok, J Dekker Genetics Newcastle-upon-Tyne, UK: S Patel, M Walker Stable Isotope Laboratory, Pisa, Italy: A Gastaldelli, D Ciociaro Ultrasound Reading Centre, Pisa, Italy: M Kozakova ECG Reading, Villejuif, France: MT Guillanneuf

Data Management, Villejuif, France: B Balkau, L Mhamdi; Padova, Italy: A Mari; Pisa, Italy: L Mota

Mathematical Modeling and Website Management, Padova, Italy: A Mari, G Pacini, C Cavaggion

Coordinating office: Pisa, Italy: SA Hills, L Landucci, L Mota.

\section{REFERENCES}

1 Poirier P, Giles TD, Bray GA, Hong Y, Stern SJ, Pi-Sunyer X et al. Obesity and cardiovascular disease: Pathophysiology, evaluation and effect of weight loss. An update of the 1997 American Heart Association Scientific Statement on Obesity and Heart Disease from the Obesity Committee of the Council on Nutrition, Physical Activity, and Metabolism. Circulation 2006; 113: 898-918.

2 Bastien M, Poirier P, Lemieux I, Després JP. Overview of epidemiology and contribution of obesity to cardiovascular disease. Prog Cardiovasc Dis 2014; 56: 369-381.

3 Dalmas E, Kahn FJ, Giral P, Abdennour M, Bouillot JL, Fellahi S et al. Intima-media thickness in severe obesity. Diabetes Care 2013; 36: 3793-3802.

4 Kotsis VT, Stabouli SV, Papamichael CM, Zakopoulos NA. Impact of obesity in intima-media thickness of carotid arteries. Obesity 2006; 14: 1708-1715.

5 Van Gaal LF, Mertens IL. Overweight, obesity, and blood pressure: the effects of modest weight reduction. Obesity 2000; 8: 270-278.

6 Messerli FH, Ventura HO, Reisin E, Dreslinski GR, Dunn FG, MacPhee AA et al. Borderline hypertension and obesity: two prehypertensive states with elevated cardiac output. Circulation 1982; 66: 55-60.

7 de Simone G, Devereux RB, Daniels SR, Mureddu G, Roman MJ, Kimball TR et al. Stroke volume and cardiac output in normotensive children and adults. Assessment of relations with body size and impact of overweight. Circulation 1997; 95: 1837-1843.

8 Collis T, Devereux RB, Roman MJ, de Simone G, Yeh JL, Horward BV et al. Relations of stroke volume and cardiac output to body composition. The Strong Heart Study. Circulation 2001; 103: 820-825.

9 Alpert MA, Omran J, Mehra A, Ardhanari S. Impact of obesity and weight loss on cardiac performance and morphology in adults. Prog Cardiovasc Dis 2014; 56: 391-400.

10 Sho E, Nanjo H, Sho M, Kobayashi M, Komatsu M, Kawamura $K$ et al. Arterial enlargement, tortuosity, and intimal thickening in response to sequential exposure to high and low wall shear stress. J Vasc Surg 2004; 39: 601-612.

11 Jones EC, Devereux RB, O'Grady MJ, Schwartz JE, Liu JE, Pickering TG et al. Relation of hemodynamic volume load to arterial and cardiac size. J Am Coll Cardiol 1997; 29: 1303-1310.

$12 \mathrm{Hu} \mathrm{JJ}$, Fossum TW, Miller MW, Xu H, Liu S, Humphrey JD. Biomechanics of the basilar artery in hypertension. Annl Biomed Engr 2007; 35: 19-29.

13 Matsumoto T, Hayashi K. Mechanical and dimensional adaptation of rat aorta to hypertension. ASME J Biomech Eng 1994; 116: 278-283.

14 Saas C, Herberth B, Chapet O, Siest G, Visvikis S, Zannad F. Intima-media thickness and diameter of carotid and femoral arteries in children, adolescents and adults from the Stanislas cohort: effect of age, sex, anthropometry and blood pressure. J Hypertens 1998; 16: 1593-1602.

15 Humphrey JD. Vascular adaptation and mechanical homeostasis at tissue, cellular and sub-cellular levels. Cell Biomech Biophys 2008; 50: 53-78.

16 De Simone G, McClelland R, Gottdiener JS, Celentano A, Kronmal RA, Gardin JM. Relation of hemodynamics and risk factors to ventricular-vascular interactions in the elderly: the Cardiovascular Health Study. $J$ Hypertens 2001; 19: 1893-1903.

17 Sarkola T, Manlhoit C, Slorach C, Bradley TJ, Hui W, Mertens L et al. Evolution of the arterial structure and function from infancy to adolescence is related to anthropometric and blood pressure changes. Arterioscler Thromb Vasc Biol 2012; 32: 2516-2524.

18 Chung WB, Hamburg NM, Holbrook M, Shenouda SM, Dohadwala MM, Terry DF et al. The brachial artery remodels to maintain local shear stress despite the presence of cardiovascular risk factors. Arterioscler Thromb Vasc Biol 2009; 29: 606-612.

19 Girerd X, London G, Boutouyrie P, Mourad JJ, Safar M, Laurent S. Remodeling of the radial artery in response to chronic increase in shear stress. Hypertension 1996; 27: 799-803.

20 Glagov S, Vito R, Giddens DP, Zarins CK. Micro-architecture and composition of artery walls: relationship to location, diameter and the distribution of mechanical stress. J Hypertens (Suppl) 1992; 10: S101-S104.
21 Bots ML, Hofman A, Grobbee DE. Increased common carotid artery intima-media thickness. Adaptive response or a reflection of atherosclerosis? Finding from the Rotterdam study. Stroke 1997; 28: 2442-2447.

22 Chironi GN, Simon A, Bokov P, Levenson J. Correction of carotid intima-media thickness for adaptive dependence on tensile stress: implication for cardiovascular risk assessment. J Clin Ultrasound 2009; 37: 270-275.

23 Kozakova M, Palombo C, Paterni M, Arnwald CH, Konrad T, Colgan MP et al. Relationship between Insulin Sensitivity Cardiovascular risk Investigators. Body composition and common carotid artery remodeling in a healthy population. J Clin Endocrinol Metab 2008; 93: 3325-3332.

24 Bokov P, Chironi G, Orobinskaia L, Flaud P, Simon A. Carotid circumferential wall stress homeostasis in early remodeling: theoretical approach and clinical application. J Clin Ultrasound 2012; 40: 486-492.

25 Hills SA, Balkau B, Coppack SW, Dekker JM, Mari A, Natali A et al. EGIR-RISC Study groups. The EGIR-RISC Study (The European group for the study of insulin resistance; relationship between insulin sensitivity and cardiovascular risk): I. Methodology and objectives. Diabetologia 2004; 47: 566-570.

26 Grundy SM, Pasternak R, Greenland P, Smith S Jr, Fuster V. Assessment of cardiovascular risk by use of multiple-risk-factor assessment equations: a statement for healthcare professionals from the American Heart Association and the American College of Cardiology. Circulation 1999; 100: 1481-1492.

27 Expert panel on detection, evaluation, and treatment of high blood cholesterol in adults. Executive Summary of the Third Report of the National Cholesterol Education Program (NCEP) Expert Panel on Detection, Evaluation, and Treatment of High Blood Cholesterol in Adults (Adult Treatment Panel III). JAMA 2001; 285: 2486-2497.

28 Touboul PJ, Hennerici MG, Meairs S, Adams H, Amarenco P, Bornstein N et al. Mannheim carotid intima-media thickness consensus (2004-2006-2011). An update on behalf of the Advisory Board of the 3rd, 4th and 5 th Watching the Risk Symposium, 13th, 15th and 20th European Stroke Conferences, Mannheim, Germany, 2004, and Brussels, Belgium, 2006, and Hamburg, Germany 2011. Cerebrovasc Dis 2012; 34: 290-296.

29 Kozakova M, Natali A, Dekker J, Beck-Nielsen H, Laakso M, Nilsson P et al. RISC Investigators. Insulin sensitivity and carotid intima-media thickness: relationship between insulin sensitivity and cardiovascular risk study. Arterioscler Thromb Vasc Biol 2013; 33: 1409-1417.

302000 CDC growth charts for the United States: Methods and development. Data From the National Health Examination Surveys and the National Health and Nutrition Examination Surveys. DHHS Publication No. (PHS) 2002-1696.

31 Unthank JL, Fath SW, Burkhart HM, Miller SC, Dalsing ME. Wall remodeling during luminal expansion of mesenteric arterial collaterals in the rat. Circ Res 1996; 79: 1015-1023.

32 Lehman RM, Owens GK, Kassel NF, Hongo K. Mechanism of enlargement of major cerebral collateral arteries in rabbits. Stroke 1991; 22: 499-504.

33 Sindermann JR, Babij P, Klink JC, Köbbert C, Plenz G, Ebbing J et al. Smooth muscle-specific expression of SV40 large TAg induces SMC proliferation causing adaptive arterial remodeling. Am J Physiol Heart Circ Physiol 2002; 283: $\mathrm{H} 2714-\mathrm{H} 2124$

34 Bonniton-Kopp C, Touboul PJ, Berr C, Magne C, Ducimetière P. Factors of carotid arterial enlargement in a population aged 59 to 71 years. The EVA Study. Stroke 1996; 27: 654-660.

35 Ruan L, Chen W, Srinivasan SR, Sun M, Wang H, Toprak A et al. Correlates of common carotid artery diameter in black and white younger adults. The Bogalusa Heart Study. Stroke 2009; 40: 702-707.

36 Crouse JR, Goldbourt U, Evans G, Pinsky J, Sharrett AR, Sorlie P et al. Arterial enlargement in the Atherosclerosis Risk in Communities (ARIC) cohort: in vivo quantification of carotid arterial enlargement. The ARIC Investigators. Stroke 1994; 25: $1354-1359$.

37 Kappus RM, Fahs CA, Smith D, Horn GP, Agiovlasitis S, Rossow L et al. Obesity and overweight associated with increased carotid diameter and decreased arterial function in young otherwise healthy men. Am J Hypertens 2014; 27: 628-634.

38 Jounala M, Raitakari M, Viikari JSA, Raitakari OT. Obesity in youth is not an independent predictor of carotid IMT in adulthood. The Cardiovascular Risk in Young Finns Study. Atherosclerosis 2006; 185: 388-393.

39 Freedman DS, Dietz WH, Tang R, Mensah GA, Bond MG, Urbina EM et al. The relation of obesity throughout life to carotid intima-media thickness in adulthood: The Bogalusa Heart Study. Int J Obes Telat Metab Disord 2004; 1: 159-166.

40 Charakida M, Jones A, Falaschetti E, Khan T, Finer N, Sattar N et al. Childhood obesity and vascular phenotypes. A population study. J Am Coll Cardiol 2012; 60: 2643-2650.

41 Alpert MA. Obesity cardiomyopathy: pathophysiology and evolution of the clinical syndrome. Am J Med Sci 2001; 321: 225-236.

42 Messerli FH. Cardiopathy of obesity-a not-so-Victorian disease. N Engl J Med 1986; 314: 378-380 
43 Rider OJ, Francis JM, Ali MK, Byrne J, Clarke K, Neubauer S et al. Determinant of left ventricular mass in obesity; a cardiovascular magnetic resonance study. J Cardiovasc Magnetic Res 2009; 11: 1-9.

44 Alter P, Rupp H, Stoll F, Adams P, Figiel J, Klose KJ et al. Increased enddiastolic wall stress precedes left ventricular hypertrophy in dilative heart failure-use of the volume-based stress index. Int J Cardiol 2012; 157: 233-238.

45 Frystyk J, Skjærbæk C, Vestbo E, Fisker S, Ørskov H. Circulating levels of insulin-like growth factors in obese subjects: the impact of type 2 diabetes. Diabetes Metab Res Rev 1999; 15: 314-322.

46 Straczkowski M, Karczewska-Kupczewska M, Adamska A, Otziomek E, Nikalajuk A. Serum fibroblast growth factor 21 in human obesity: regulation by insulin infusion and relationship with glucose and lipid oxidation. Int J Obes 2013; 37 1386-1390.

47 Kawachi S, Takeda N, Sasaki A, Kokubo Y, Takami K, Sarui H et al. Circulating insulinlike growth factor-1 and insulin-like growth factor binding protein-3 are associated with early carotid atherosclerosis. Arteriosler Thromb Vasc Biol 2005; 25: 617-621.

48 Chou WS, Xu A, Woo YC, Tso AW, Cheung SC, Fong $\mathrm{CH}$ et al. Serum fibroblast growth factor-21 levels are associated with carotid atherosclerosis independent of established risk factors. Arteriosler Thromb Vasc Biol 2013; 33 2454-2459.
49 Verdecchia P, Reboldi C, Schillaci G, Borgioni C, Ciucci A, Telera MP et al. Circulating insulin and insulin growth factor-1 are independent determinants of left ventricular mass and geometry in essential hypertension. Circulation 1999; 100 1802-1807.

50 Nichols WW, O'Rourke MF Contours of pressure and flow waves in arteries. In:McDonald's Blood Flow (eds). Arteries Theoretical, Experimental and Clinical Principles 5th edn, Hooder Arnold: London, 2005, pp 165-191.

51 Chan EJ, Alpert MA. Cardiovascular physiology in Obesity. In: Critical Care Management of the Obese Patient 1st edn, John Wiley \& Sons: Hoboken, NJ, USA 2012, pp 3-12.

This work is licensed under a Creative Commons Attribution 4.0 International License. The images or other third party material in this article are included in the article's Creative Commons license, unless indicated otherwise in the credit line; if the material is not included under the Creative Commons license, users will need to obtain permission from the license holder to reproduce the material. To view a copy of this license, visit http://creativecommons.org/licenses/ by/4.0/

Supplementary Information accompanies this paper on the Nutrition \& Diabetes website (http://www.nature.com/nutd) 